\title{
Một nơi giới thiệu bayesvl
}

Nguyễn Minh Hoàng; email: ng.19m6tk@apu.ac.jp

Ngày 11-2-2022, Tp. HCM

Nhóm nghiên cứu AISDL đang có tối thiểu 5 bản thảo nộp cho các tạp chí khoa học khác nhau đã được gửi đi bình duyệt, ở các trạng thái gần-xa đa dạng.

Tôi chợt tự đặt ra câu hỏi, điều gì xảy ra nếu như vào những tháng năm này, chương trình bayesvl trên $\mathrm{R}$ chưa sẵn sàng để phục vụ đội ngũ nghiên cứu? [1]

(Ghi chú: Tất cả các nghiên cứu gửi đi kia đều xử lý dữ liệu với bayesvl.)

Bỗng thấy thật là khó hình dung, vì câu trả lời sẽ là: rất nhiều thiệt thòi về cả năng suất, mức độ đa dạng, khả năng vượt qua bình duyệt, v.v.. Package bayesvl đã hỗ trợ đội ngũ hết sức hiệu quả, khó mà nói hết. Tình cờ, hôm nay lang thang trên mạng, lại gặp một nơi giới thiệu chương trình này, tại địa chỉ: https://swmath.org/software/39027

Hình ảnh screenshot:

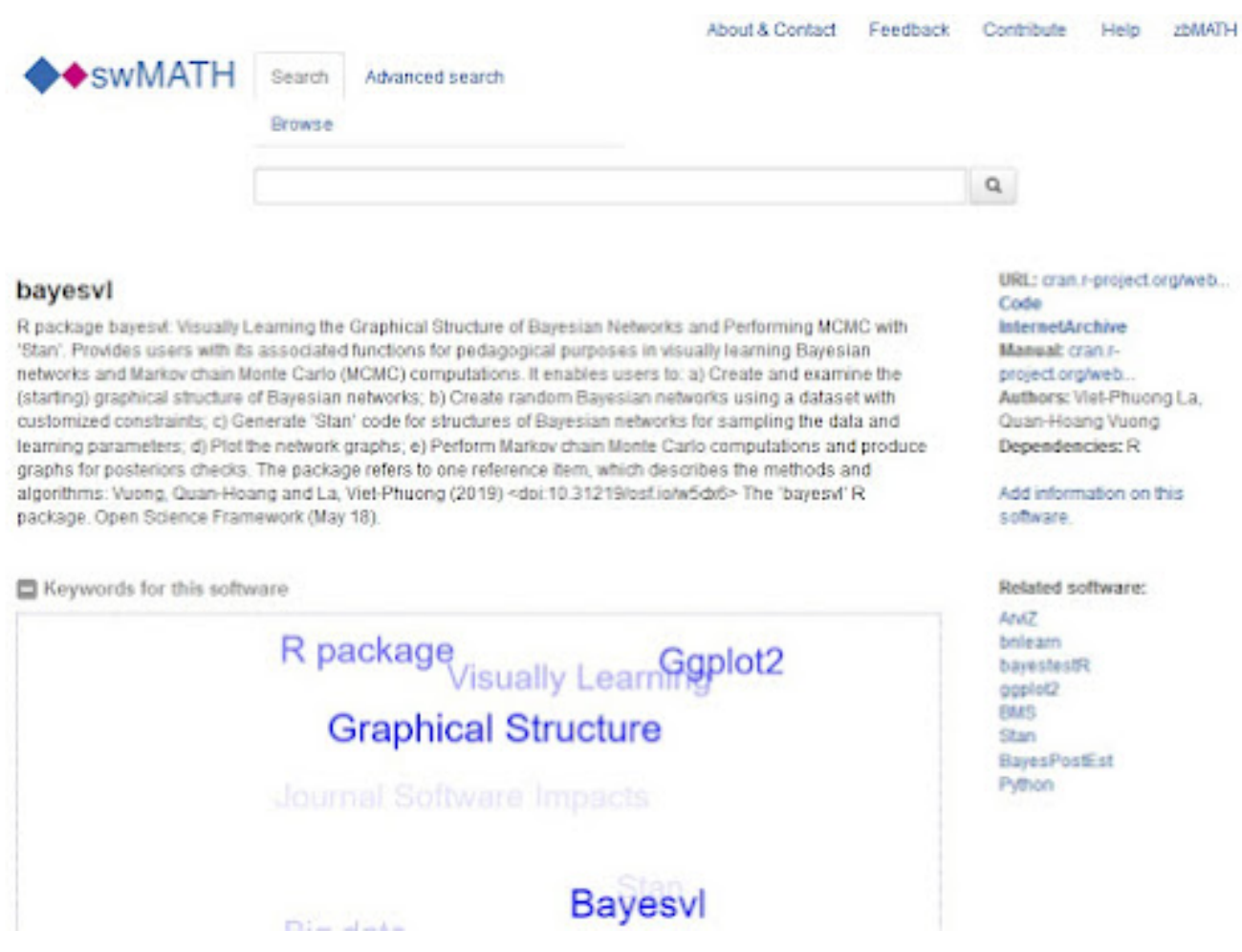

Cá nhân tôi còn nhận thấy, nếu xét từ góc nhìn tiết kiệm chi phí và hiệu quả đầu tư [2], thì chương trình bayesvl là cứu cánh. Trong quá trình hoàn thành luận án tiến sỹ của mình tại Ritsumeikan Asia Pacific University, nó đã giúp tôi giải tỏa một gánh nặng lớn về kinh phí triển khai nghiên cứu do không đòi hỏi lượng dữ liệu quá lớn, vốn dĩ chiếm tỷ trọng rất đáng kể trong các chương trình nghiên cứu. 


\section{References}

[1] La, V. P., \& Vuong, Q. H. (2019). Package 'bayesvl': Visually Learning the Graphical Structure of Bayesian Networks and Performing MCMC with 'Stan'. The Comprehensive $R$ Archive Network (CRAN). Retrieved from: https://CRAN.R-project.org /package=bayesvl

[2] Vuong, Q. H. (2018). The (ir)rational consideration of the cost of science in transition economies. Nature Human Behaviour, 2(1), 5. 